\title{
Comprehensive Analysis of Homologous Proteins for Specific Drug Design
}

\author{
Bharath $\mathrm{BR}^{1,2 \star}$, Sujata Barangi ${ }^{1}$, Rajesh $\mathrm{KP}^{2}$, Chetan DM and Manjunatha $\mathrm{H}^{2}$ \\ ${ }^{1}$ Department of Biotechnology, N.M.A.M. Institute of Technology, Nitte- 574 110, Karkala, Karnataka, India \\ ${ }^{2}$ Department of P.G Studies and Research in Biotechnology and Bioinformatics, Kuvempu University, \\ Jnanasahyadri, Shankaraghatta - 577 451, Shimoga, Karnataka, India
}

\begin{abstract} predicted as a good antibiotic against Aeromonas Species.

\section{INTRODUCTION}

A drug, is any substance that, when absorbed into the body of a living organism, alters normal bodily function. In the field of pharmacology, a drug can be defined as a chemical substance used in the treatment, cure or prevention of disease otherwise used to enhance physical or mental well-being. Drugs must be not only effective but safe; side-effects can range from minor to dangerous.
\end{abstract}

A drug is a chemical substance used in the diagnosis, treatment or prevention of disease or as a component of a medication, should be specific and freedom from side affect. Many issues should be addressed while designing a new drug or improving existing compound. The increase in the interdisciplinary nature of science gives bioinformatics, systems and computational biology, which helps in reducing research and development costs, minimize drug failures by predicting drug efficacy and toxicity. One of the most important pathogenic bacterium is Aeromonas species which causes tissue damage, acute gastroenteritis and neonatal septicemia. Bacterial proteins are the ultimate target to inhibit their growth and these are the executors of cellular function. In related to this we selected four such different proteins Flavohemo protein, Guanylate kinase, Topoisomerase and Oligopeptidase found to be present in both humans and Aeromonas to study the effects of antibiotics through in silico approaches. An attempt has been made to classify the inhibitors as host protein inhibitors or guest protein inhibitors. Finally we conclude that the molecule Agkl5 (2-morpholin-4-yl-thianthren-1-ylpyron-4-one) shown good inhibition with minimum binding energy -9.30 , docking energy -10.03 , inhibition constant 1.53e-007 and RMS 0.0 against Aeromonas Guanylate kinase [Aeromonas: Modelled] when compared to human Guanylate kinase [PDB ID: 1KJD]. So Agkl5 was

Copyright@2014 STAR Journal. All Rights Reserved.

\section{Article Information}

Article History:

Received : 20-02-2014

Revised : 25-05-2014

Accepted : 28-05-2014

Keywords:

Aeromonas species

Host

Guest

Guanylate kinase Docking

Protein Inhibitors

${ }^{*}$ Corresponding Author:

Bharath BR

E-mail:

bharathbasavapattan@gmail.com
Humans have been Figurehting against bacterial pathogens for many decades. Since, then humans have been utilizing various chemical substances with antibacterial or bacteriostatic properties. In the past 50 years, borrowing anti-bacterials from other bacteria and fungi even produced an impression of success in this battle (Galperin et al., 1999).

The bactericidal antibiotic killing mechanisms are currently attributed to the class-specific drug-target interactions. Current antimicrobial therapies, which cover a wide array of targets, fall into two general categories: bactericidal drugs-which kill bacteria with an efficiency of $>99.9 \%$ and bacteriostatic drugs- which merely inhibit growth (Michael et al., 2007).

Bacteria belonging to Aeromonas species have been identified as common enteric pathogens from several countries. They cause acute gastroenteritis of both adults and children's, ranging from watery to blood diarrhoea of either short or prolonged (over 2 weeks) duration. In mammals, Aeromonas species causes neonatal septicemia (Bharath and Manjunatha, 2013). They occur widely in the environment, especially in water. They are found in both raw and chlorinated water supplies (Kudinha et al., 2004).

Aeromonas hydrophila, Aeromonas caviae, and Aeromonas sobria are all considered to be "opportunistic pathogens," meaning they only infect hosts with weakened immune responses. Because of Aeromonas hydrophila's structure, it is very toxic to many organisms. When it enters the body of its victim, it travels through the bloodstream to the first available organ. It produces Aerolysin Cytotoxic Enterotoxin (ACT), a toxin that can cause tissue damage (Chopra et al., 2000). Though Aeromonas hydrophila is considered a pathogenic bacterium, scientists not been able to prove that it is the actual cause of some of the diseases it is associated with. It is believed that this bacterium aids in the infection of diseases, but do not cause the diseases themselves.

Foods have been implicated in the transmission of Aeromonas species. Motile Aeromonas have been 
Bharath et al.,

isolated from fresh foods of animal origin. The microorganism has the potential to be a food borne pathogens. The disease spectrum associated with these microorganisms includes gastroenteritis, Septicemia, aquatic wound infections (Kudinha et al., 2004).

Proteins are the ultimate executors of cellular function, and thus are directly responsible for a biological phenotype (Anderson et al., 2002). Proteomics is the study of the expression, modification and activity of proteins in order to better understand a biological system. Diseased (or drug treated lysates) are identically processed and comparative analysis performed to evaluate protein expression between the two samples (Aebersold et al., 2003). So in the present study, we selected four different proteins present in both Aeromonas and human system they are Guanylate Kinase protein, Oligopeptidase protein, Flavohemoprotein and Topoisomerase protein by functional analysis we will come to know that whether the proteins are orthologs or not using molecular docking studies as the force field is based on the concept of residue- residue contact energies. Reduced structures can be translated to atomic resolution, and further evaluated (Andrzej et al., 2003).

\section{MATERIALS AND METHODS}

Sequence, structure and domain analysis was performed to predict the efficacy of inhibitor molecules against proteins. Protein sets were downloaded by Integr8 database and protein families were studied in Interpro, and then BLAST was performed for protein sequences against PDB to verify about the availability of structural information. BLAST and Genius clustalW tools were employed for sequence analysis. Structure analysis was performed using PDB database and protein homology modeling was achieved in Swiss modeler and validated through ADIT validation server by plotting Ramachandran plot for some proteins whose structural information was not available in PDB, Topmatch server was used for protein superimposition. Domain analysis was performed
Sci. Technol. Arts Res. J., April-June 2014, 3(2): 47-62

for all the proteins using Prosite server. Molecular docking studies were done using AutoDock v3.0 for known inhibitors downloaded from PubChem against selected proteins. An attempt has been made to classify the inhibitors as human protein inhibitors or Aeromonas protein inhibitors.

\section{RESULTS AND DISCUSSION}

From the integr8, we have downloaded the proteomic sets of human and bacteria. Interpro IDs From that proteome set were taken and submitted for Interpro, which shows the protein family, out of them we have selected four families and cross referenced with Pfam database for confirmation and selected four below showed in Table 1. The protein sequences for Guanylate kinase, Oligopeptidase, Flavohemoprotein and DNA Topoisomerase with a Uniprot ID's AOKEC4, AOKEG4, AOKG18 and A5UCC4 respectively in FASTA format were collected and subjected for sequence analysis.

Table 1: The Pfam IDs for four proteins

\begin{tabular}{ll}
\hline \multicolumn{1}{c}{ Protein } & Pfam ID \\
\hline Guanylate kinase & PF00625 \\
Oligopeptidase A & PF01432 \\
Flavohemoprotein & PF00175 \\
Topoisomerase & PF00204 \\
\hline
\end{tabular}

\section{Sequence Analysis}

psi-BLAST was performed for Flavohemoprotein, Guanylate kinase, Topoisomerase and Oligopeptidase protein sequences in FASTA format against nonredundant database, and the sequences from different species from Human to bacteria were selected from the obtained hits (Stephen et al., 1997). The Multiple Sequence Alignment was performed for the selected sequences using T-coffee to analyze the conserved regions (Figure 1-4).

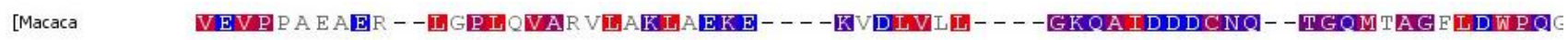

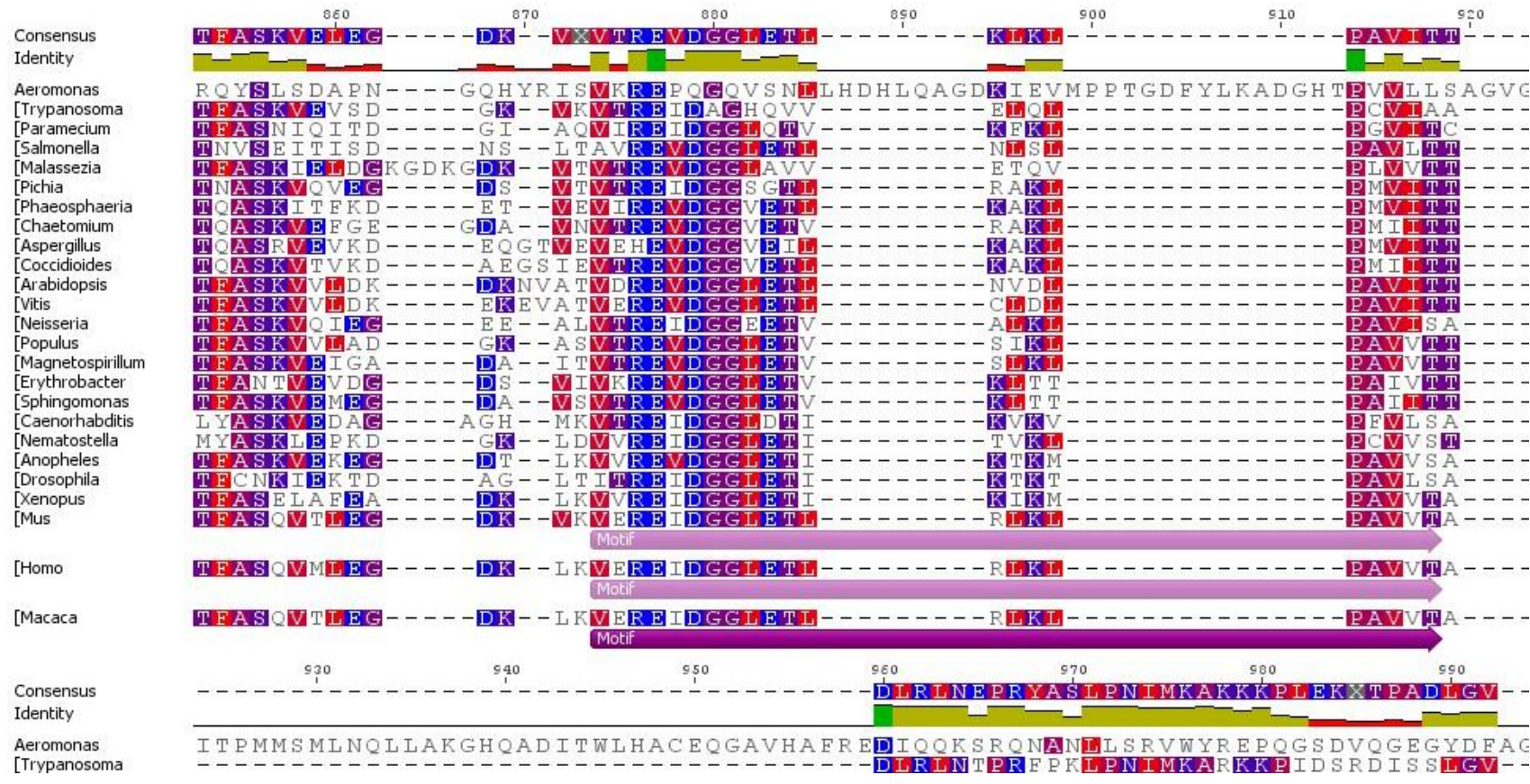

Figure 1: Flavohemoprotein. 


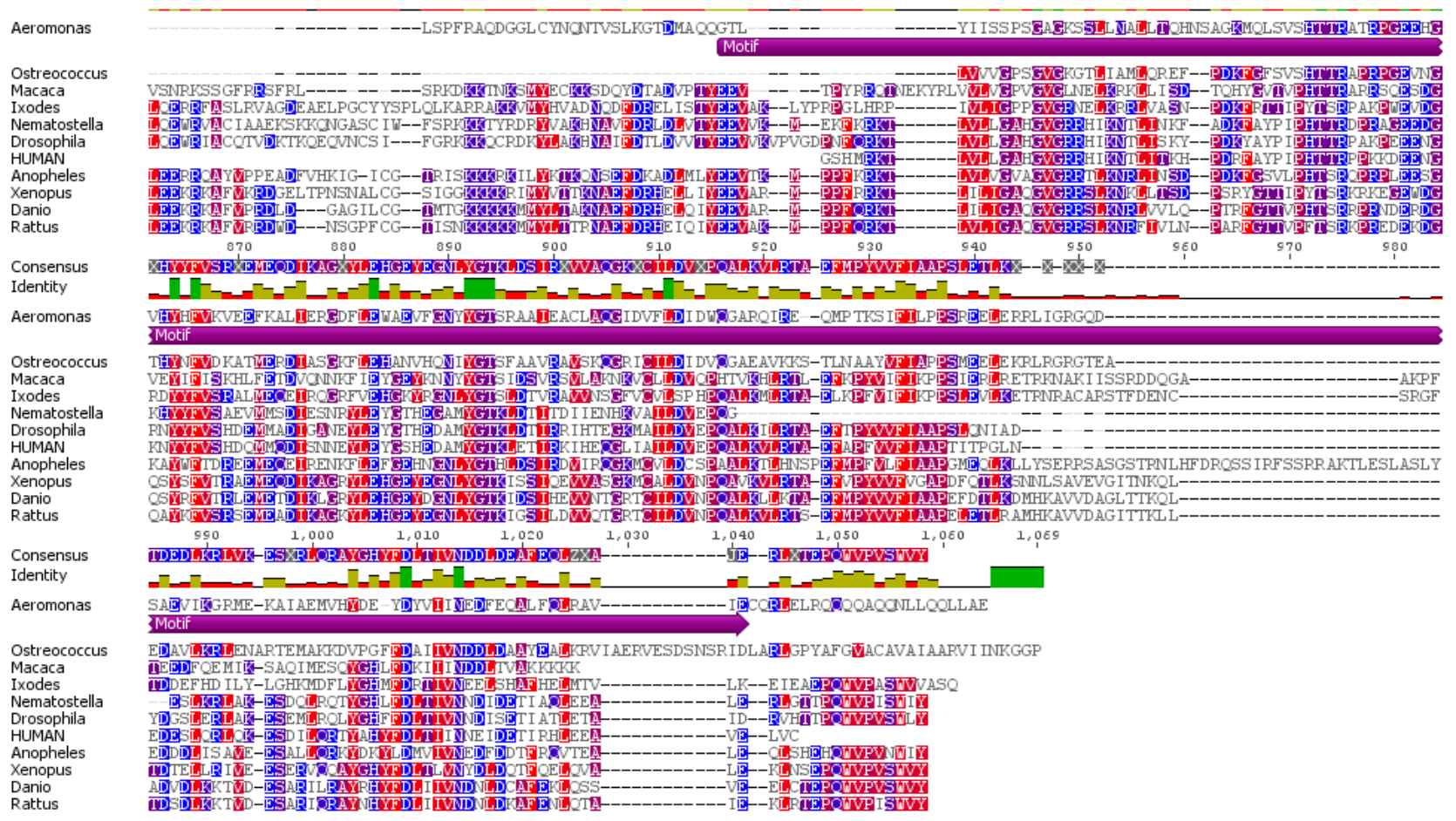

Figure 2: Guanylate kinase.

Liıanuveua
Drosophila
Gallus
A6NDMOA6NDM0_HUMAN
Mus
Rattus
Ostreococcus
Saccharomyces
Aspergillus
Penicillium
Coprinopsis
Cryptococcus
Consensus
Identity
Aeromonas 2
E.
Enterobacteria
Aeromonas
Trichomonas
Chlorella
Plasmodium
Plasmodium 2
Entamoeba
Drosophila
Gallus
A6NDMO|A6NDM0_HUMAN
Mus
Rattus
Ostreococcus
Saccharomyces
Aspergillus
Penicillium
Coprinopsis
Cryptococcus
Consensus
Identity
Aeromonas 2

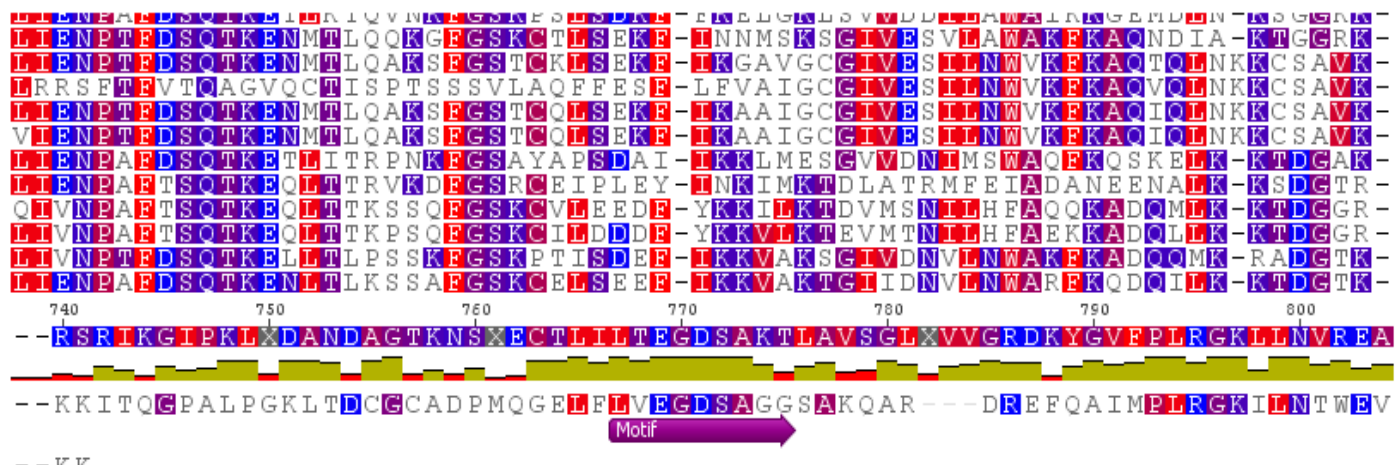
$--\mathrm{KK}$

$--$

- - K GRL I INKLEDANMAGKA ESL KCTL I L T EGDSAKA TAVTGLA T IGRDYYGVFP LRGKL LN TRD I $--K$ TRL TGIKKL TDAA WAGTKNSG LCTLILTEGDSAATLATAGLAVVGRER YGIEPLRGKL LNVRDA

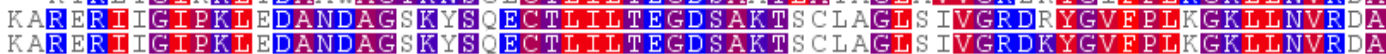
KARERIIGIPKLEDANDAGSKYSQECTL I T EGDSAKTSCLAGLS IVGRDKYGVFPLKGKL LNVRDA - - TARITGIPKLDDANKAGTKE GN LCTL I T EGDSAKT LAVSGLSVVGRDYYGVF LRGKP LNAREI - - SSK IKGIPKLEDANEAGGKNSI KCTL I T EGDSAKS LAVSGLGVIGRDLYGVFP LRGKL LNVREA - - T TIKGVPKLDDANDAGSKNSIDCTLI T EGDSAKT LAVSGLGVVGRDKYGVF LRGKMLNVREA

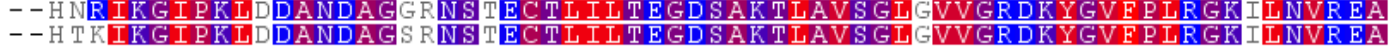

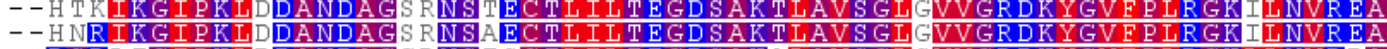
- -RSRLTGIPKLDDANDAGGRISE SCTLILTEGDSAKALAVSGLSVVGRDKYGVFPLRGKLLNVRDA - - KSRIT NYPKLEDANKAGTKEGYKCTLVITEGDSAL S LAVAGLAVVGRDYYGCYPLRGKMLNVREA - -RARMN N PKL TANKAGTKD G HCTLILTEGDSAKGLAMAGR AVVGPDL FGVF PRGKLLNVRDA - -RSRMNN-PKLTDANKAGTKD GH HCTLILTEGDSAKGLAMAGR AVVGPDL FGVFPLRGKL LNVRDA - -RSRL LGL AKL S DANNAGTR H A DCTLILTEGDSAKALAIAGLGVVGRDNEGVFPLRGKL LNVR EA - -RSRISGIVKLEDANNAGGRISK NCTLILTEGDSAKALAVSGIAVVGRDEYGVEPLRGKLLNVREA

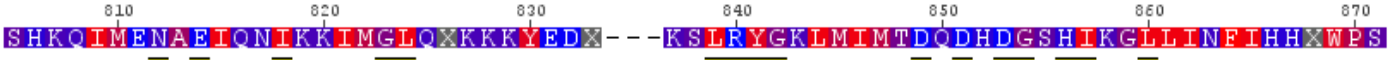

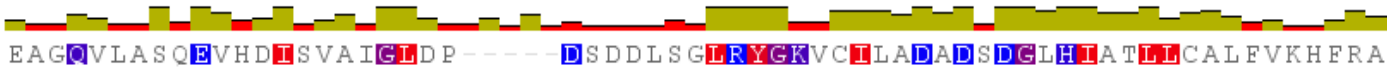

Figure 3: Topoisomerase.

The BLAST against Non-Redundant Database was performed for the FASTA sequences, numbers of hits for same protein were obtained, we have selected these sequences from different species and the FASTA sequences were downloaded. For downloaded sequences we performed Multiple Sequence Alignment using Genius
Pro. (Figure 1-4). Here conserved regions among Aeromonas, Human and other species were analyzed, by this MSA we can say that the proteins both in Human and Bacteria performs same functions due to the conservation of the particular amino acid residues in their motifs. 


[Schistosoma
[Gallus
[Sus
[Xenopus

[Rattus

[Homo
[Macaca
[Tetraodon

[Danio

[Salmo
[Branchiostoma
[Nematostella
[Laccaria
[Podospora
[Aspergillus
[Ajellomyces
[Paracoccidioides
[Saccharomyces
[Candida
[Zygosacharomyces
[Bacteroides
[Flavobacteria
[Polaribacter
[Deinococcus
[gamma
[marine
[Chromohalobacter
[Pseudomonas
[Oceanospirillum
[Aeromonas
[Actinobacillus
[Pectobacterium
[Citrobacter
[Fsrherirhia

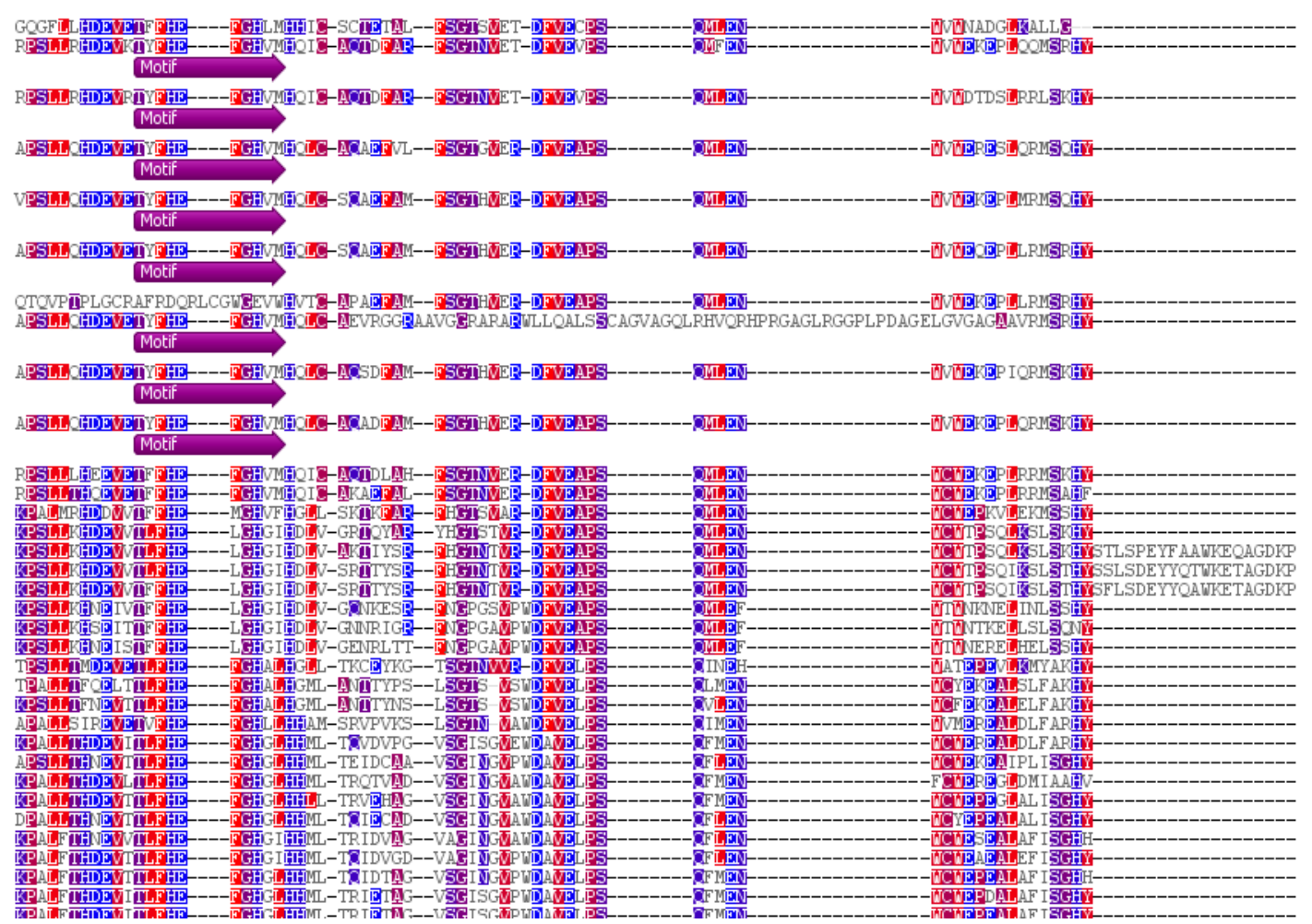

Figure 4: Oligopeptidase.

\section{Domain Analysis}

Domain analysis of these four proteins was done using PROSITE server. Here domains of Aeromonas protein are compared with the domains of human proteins. The domain hits obtained for Human guanylate kinase protein and Aeromonas Guanylate kinase sequences were observed with Guanylate Kinase_2 domain (Figure 5a and 5b) at $701^{\text {th }}$ to $880^{\text {th }}$ residue and $81^{\text {th }}$ to $261^{\text {th }}$ residue respectively, this indicates the domain shifting. Human guanylate kinase was observed with five more domains such as PROTEIN KINASE_OOM, two L27 domains, PDZ and $3 \mathrm{H} 3$ domains which were not seen on Aeromonas sequence (Laurent et al., 2002).

ruler:
hits by profiles: [6 hits (by 5 distinct profiles) on 1 sequence]
-HOMO

Figure 5a: Human Guanylate kinase.

ruler:

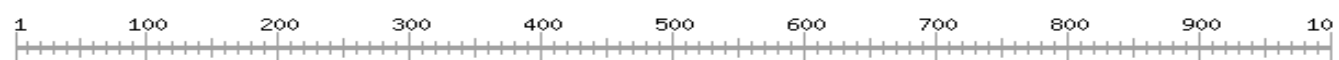

hits by profiles: [1 hit (by 1 profile) on 1 sequence]

Hits by PS50052 GUANYLATE_KINASE_2 Guanylate kinase-like domain profile

81 - 261: $\quad$ score $=36.165$

GTIYIISSPSGAGKSSILNAIITOHNSAGKMOLSVSHTTRATRPGEEHGVHYHFVKVEEF KAIIERGDFLEWAEVFGNYYGTSRAAIEACIAQGIDVFIDIDWQGAROIREQMP-TKSIF KALIERGDFLEWAEVFGNYYGTSRAAIEACLAQGIDVFLDIDWQGARQIREQMP-TKSIF IE Predicted feature: NP_BIND

Figure 5b: Aeromonas Guanylate kinase 


\section{Bharath et al.,}

Similarly Oligopeptidase sequences were submitted and domain hits were obtained only for human sequence, no hits were found for bacterial sequence, and here we failed to observe the domain similarity between human and bacterial sequences. Neutral zinc metallopeptidases, zinc-binding region was observed on Human sequence as shown in Figure 6.

Domain analysis of Flavohemoprotein has received single hit corresponding the pattern for electron transfer flavoprotein beta-subunit on Human sequence and two
Sci. Technol. Arts Res. J., April-June 2014, 3(2): 47-62

hits by two distinct profiles namely Globin and FAD_FR on Aeromonas sequence as shown in Figure $7 a$ and $b$.

In Topoisomerase domain analysis we observed the DNA topoisomerase II domain having eight amino acids length on both the sequences Figure: $8 \mathrm{a}$ and $8 \mathrm{~b}$, on Human sequence we observed the domain from $539^{\text {th }}$ residue to $547^{\text {th }}$ residue and on Aeromonas sequence the domain was from $416^{\text {th }}$ residue to $424^{\text {th }}$ residue. Here also we can observe the domain shifting as shown in Figure $8 \mathrm{a}$ and $8 b$.

ruler:
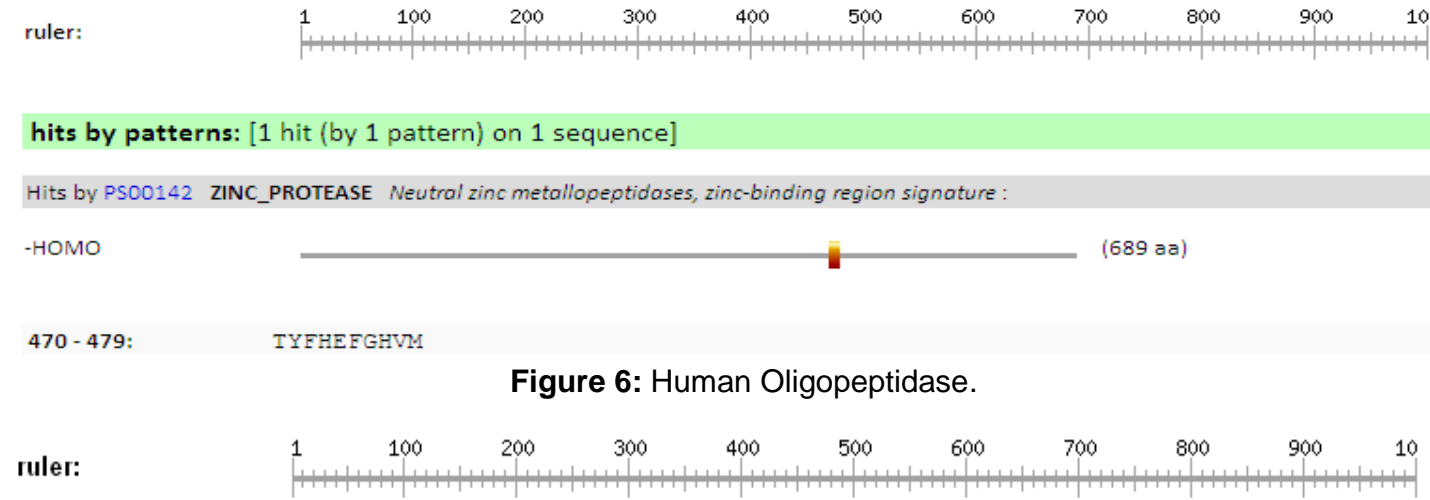

hits by patterns: [ 1 hit (by 1 pattern) on 1 sequence]

Hits by PS01065 ETF_BETA Electron transfer flavoprotein beta-subunit signature

$-\mathrm{HOMO}$

(255 aa)

$162-182:$

VeReiDGGl.EtLrlklPaVWT

Figure 7a: Human Flavohemoprotein

ruler:

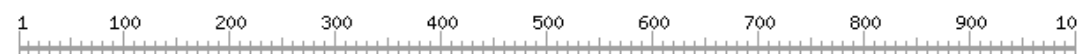

hits by profiles: [ 2 hits (by 2 distinct profiles) on 1 sequence]

$\operatorname{tr}-\mathrm{ADKG18-ADK \sim}$

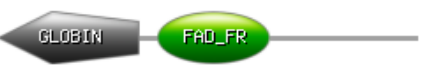

(397 aa)

\section{PS01033 GLOBIN Globin family profile}

1 - 134: $\quad$ score $=16.878$

--ML DQATT I AVI IKST IPLLES AGP AL TQHF YQR MFSHNPEL KD IFNL Ä------HQRSGGQ

PLALFNAVA------ AY AKNIDNL G--AL A GAVERI AHKHT GF L IQP-EQYH IVGSHLL

TLKEL GGS AVTDEVLD A WGKA YGVL AS IF I----

Aheont foatures

Figure 7b: Aeromonas Flavohemoprotein.

ruler:

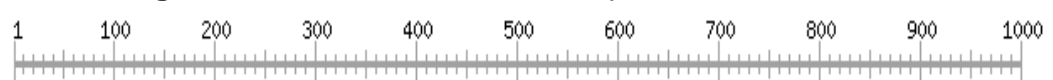

hits by patterns: [ 1 hit (by 1 pattern) on 1 sequence]

Hits by PS00177 TOPOISOMERASE_II DNA topoisomerase // signature

A6NDMO-A6NDMO

539.547

Figure 8a: Human Topoisomerase. 
ruler:

hits by patterns: [ 1 hit (by 1 pattern) on 1 sequence] Hits by PS00177 TOPOISOMERASE_II DNA topoisomerase // signature AEROMONAS

Figure 8b: Aeromonas Topoisomerase.

\section{Structural Analysis}

By domain analysis, we came to know the changes in domain composition that may lead to the structural differences. So we performed structural analysis for all the 4 proteins. For structural analysis we have collected the structures of proteins from PDB Table 1. We performed homology modeling using online modeling server Swiss model by taking $E$. coli structures as a template (Figure 9). The modeled structures were validated by ramachandran plot given by ADIT we can say that our models are good. The numbers of residues in favored region were $92.0 \%, 91.4 \%$ and $92.1 \%$ for Flavohemoprotein, Guanylate kinase and Topoisomerase respectively (Denis et al., 2002).

For structural similarity studies between Human and Aeromonas Protein structural superimposition was performed. The RMS values are 2.4, 3.3, 2.6 and 2.5 for Flavohemoprotein, Guanylate kinase, Topoisomerase and Oligopeptidase respectively as shown in Table 2 . The modeled proteien structures were subjected for active pocket prediction, for PDB structures we referred ligplot provided by PDB only and for designed models castP server was used, the amino acids in active pockets are tabulated in Table 3. Even there is no complete structural similarity, domain similarity the proteins performing the same function in human and Aeromonas (Joe et al., 2006). This led us for species specific targeting and an attempt was made to illustrate the targeting results by performing molecular docking studies.

The protein structures of Aeromonas were superimposed against human protein structures using TOPMATCH server, and also RMS value is documented in Table 2 and we can observe the super imposition in the Figure 10. The active pockets on our PDB structures were identified by referring their ligplot and for designed models we used castP server.
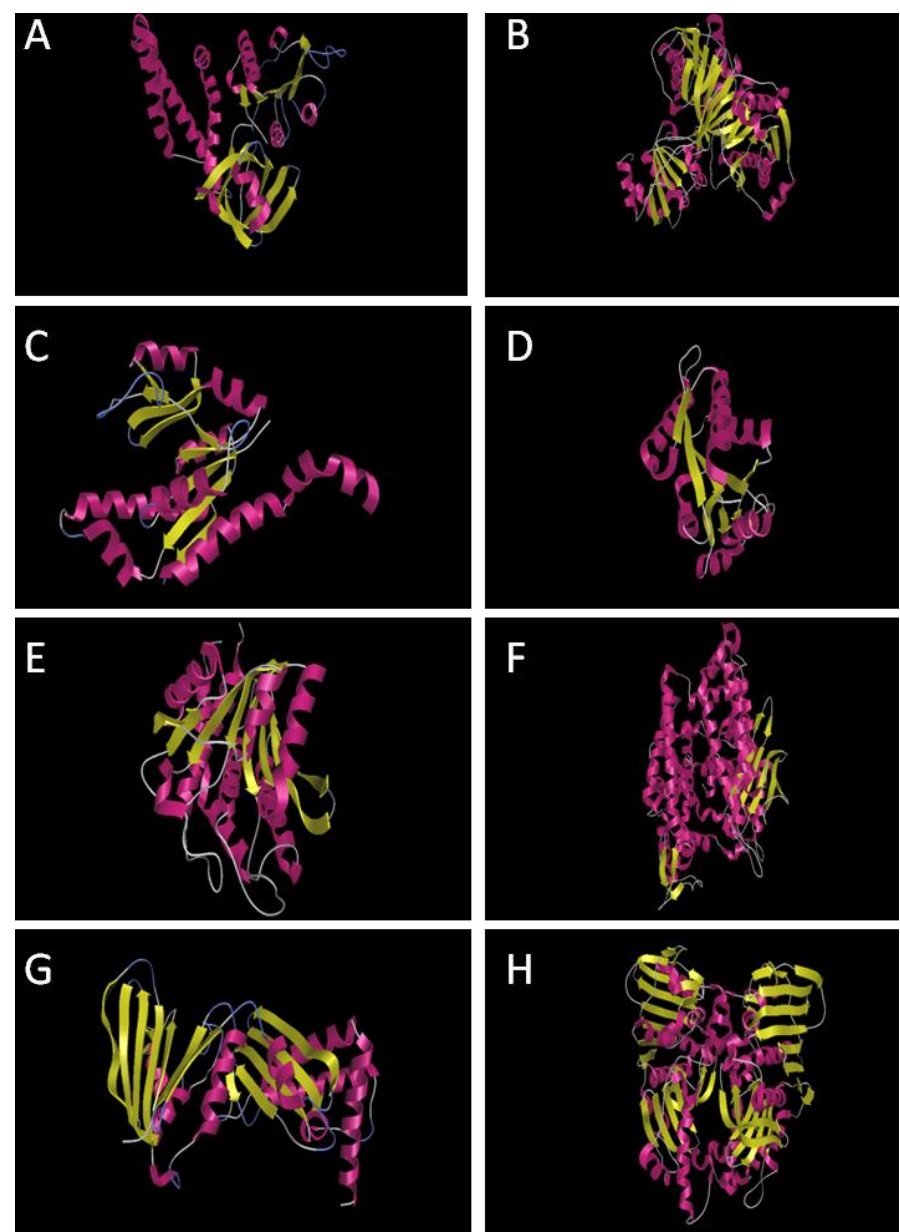

Figure 9: The protein structures of A: Aeromonas Flavohemoprotien, B: Human Flavohemoprotien, C: Aeromonas Guanylate kinase, D: Human Guanylate kinase, E: Aeromonas DNA Topoisomerase, F: Human DNA Topoisomerase, G: Aeromonas Oligopeptidase, $\mathbf{H}$ : Human DNA Oligopeptidase

Table 2: Structure superimposition using TopMatch.

\begin{tabular}{llccc}
\hline SI.No & Protein Name & Bacterial PDB ID & Human PDB ID & RMS Value \\
\hline 1. & Flavohemoprotein & Modeled & 1EFV & 2.4 \\
2. & Guanylate kinase & Modeled & 1KGD & 3.3 \\
3. & DNA Topoisomerase & Modeled & 1ZXM & 2.6 \\
4. & Oligopeptidase & 2DEA & 1S4B & 2.5
\end{tabular}


Table 3: Amino Acids in Active pocket.

\begin{tabular}{|c|c|c|c|c|}
\hline $\mathbf{N}$ & Protein Name & PDB ID & Active Pocket & $\begin{array}{l}\text { Active pocket } \\
\text { amino acids }\end{array}$ \\
\hline 1. & $\begin{array}{l}\text { Aeromonas } \\
\text { Flavohemoprotein }\end{array}$ & Modeled & $\begin{array}{l}\text { VAL-1, ALA-2, TYR-4, LYS-6, ASN-7, ALA-13, LEU-14, ALA-17, VAL- } \\
\text { 18, ARG-20, ILE-21, LYS-24, HIS-25, GLY-27, PHE-28, LEU-29, ILE- } \\
\text { 30, GLN-31, GLN-34, TYR-35, VAL-38, HIS-41, LEU-42, THR-45, LEU- } \\
\text { 46, LEU-49, TRP-62, ALA-65, TYR-66, LEU-69, ALA-70, PHE-73, } \\
\text { SER-94, GLU-105, ILE-109, SER-111, TYR-130, SER-132, LYS-134, } \\
\text { GLN-143, GLU-144, ILE-145, ARG-146, GLN-147, TYR-148, SER-149, } \\
\text { ASP-152, ARG-160, SER-162, VAL-163, LYS-164, GLU-166, PRO- } \\
\text { 167, GLN-168, GLY-169, GLN-170, VAL-171, SER-172, VAL-187, } \\
\text { MET-188, ALA-209, GLY-210, VAL-211, GLY-212, ILE-213, THR-214, } \\
\text { PRO-215, MET-217, SER-218, HIS-236, ALA-237, CYS-238, GLU-239, } \\
\text { GLN-240, ALA-242, VAL-243, HIS-244, ALA-245, PHE-246, ARG-247, } \\
\text { TYR-266, ARG-267, THR-284, GLY-304, PRO-305, VAL-306, PHE- } \\
\text { 308, MET-309, GLN-310, LYS-313, GLN-314, ILE-317, ALA-323, TYR- } \\
\text { 328, GLU-329, VAL-330, PHE-331, GLY-332. }\end{array}$ & 97 \\
\hline 2. & $\begin{array}{c}\text { Human } \\
\text { Flavohemoprotein }\end{array}$ & $1 \mathrm{EFV}$ & $\begin{array}{l}\text { ASN-132, ALA-126, ASP-129, ASN39, CYS-42, GLY-123, ALA-9, THR- } \\
\text { 134, GLN-133, CYS-66 }\end{array}$ & 10 \\
\hline 3. & $\begin{array}{l}\text { Aeromonas } \\
\text { Guanylate kinase }\end{array}$ & Modeled & $\begin{array}{l}\text { SER-27, SER-28, PRO-29, SER-30, GLY-31, LYS-34, SER-35, LEU- } \\
\text { 38, ASN-39, LEU-42, HIS-45, SER-47, MET-51, GLN-52, LEU-53, } \\
\text { SER-54, VAL-55, SER-56, HIS-57, ARG-60, ARG-63, PRO-64, VAL-70, } \\
\text { HIS-71, TYR-72, HIS-73, GLU-91, ALA-93, VAL-95, PHE-96, ASN-98, } \\
\text { TYR-100, GLY-101, THR-102, SER-103, ALA-106, ILE-107, CYS-110, } \\
\text { ILE-115, VAL-117, LEU-119, ASP-120, ILE-121, ASP-122, GLY-125, } \\
\text { ARG-151, LEU-152, ILE-153, GLY-154, ARG-155, GLY-156, GLN-157, } \\
\text { ASP-158, ARG-166, LYS-169, ALA-170, GLU-173. }\end{array}$ & 57 \\
\hline 4. & $\begin{array}{l}\text { Human Guanylate } \\
\text { kinase }\end{array}$ & $1 \mathrm{KGD}$ & GLU-802, GLY-812, TYR-811 & 3 \\
\hline 5. & $\begin{array}{l}\text { Aeromonas } \\
\text { Topoisomerase }\end{array}$ & Modeled & $\begin{array}{l}\text { ASP-2, GLN-3, SER-4, LEU-5, GLU-6, VAL-7, ILE-8, ASP-9, ASP-10, } \\
\text { GLY-11, ARG-12, GLY-13, MET-14, PRO-15, HIS-19, GLY-26, LEU-29, } \\
\text { ILE-30, ALA-36, GLY-37, GLY-38, LYS-39, PHE-40, LYS-43, ASN-44, } \\
\text { TYR-45, PHE-47, SER-48, GLY-49, GLY-50, LEU-51, HIS-52, GLY-53, } \\
\text { VLA-54, GLY-55, ILE-56, SER-57, VAL-58, VAL-59, LEU-62, SER-63, } \\
\text { ARG-72, THR-103, ARG-104, VAL-105, ARG-106, PHE-107, PRO-109, } \\
\text { PHE-114, ASP-115, SER-116, PRO-117, ARG-118, PHE-119, SER- } \\
\text { 120, VAL-121, SER-122, LYS-123, LEU-124, HIS-126, LEU-127, LEU- } \\
\text { 128, ALA-130, LYS-131, ALA-132, CYS-135, LEU-138, THR-139, ILE- } \\
\text { 140, LYS-141, PHE-142, LEU-143, ASP-144, LYS-145, ASN-146, THR- } \\
\text { 147, GLU-201, TYR-207, ASN-209, LEU-210, ILE-211, PRO-212, ALA- } \\
\text { 214, LYS-263, GLN-272, THR-273, LYS-274, GLU-275 }\end{array}$ & 87 \\
\hline 6. & $\begin{array}{c}\text { Human } \\
\text { Topoisomerase }\end{array}$ & $1 \mathrm{~S} 16$ & $\begin{array}{l}\text { ARG-162, LYS-378, ASN-163, GLN-376, ASN-150, SER-148, ASN-91, } \\
\text { SER-149, LYS-168, ALA-167, GLY-166, GLY-164, TYR-165, ASN-120. }\end{array}$ & 14 \\
\hline 7. & $\begin{array}{l}\text { Aeromonas } \\
\text { Oligopeptidase }\end{array}$ & 2DEA & 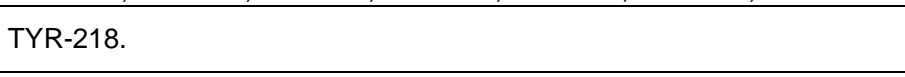 & 1 \\
\hline 8. & $\begin{array}{l}\text { Human } \\
\text { Oligopeptidase }\end{array}$ & 1S4B & HIS-473, HIS-477, GLU-502. & 3 \\
\hline
\end{tabular}
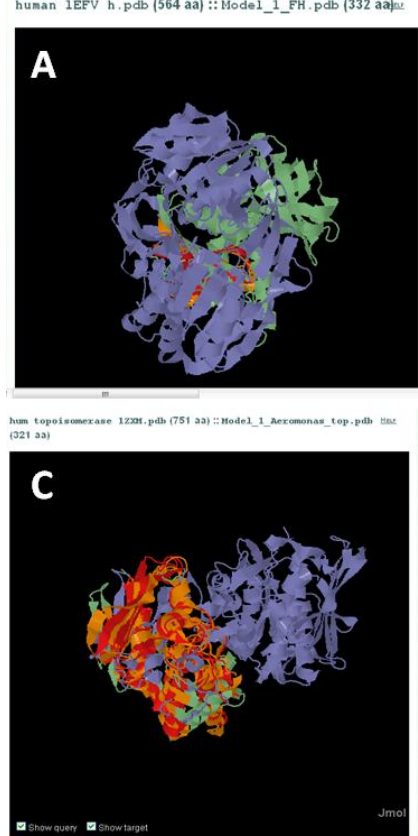
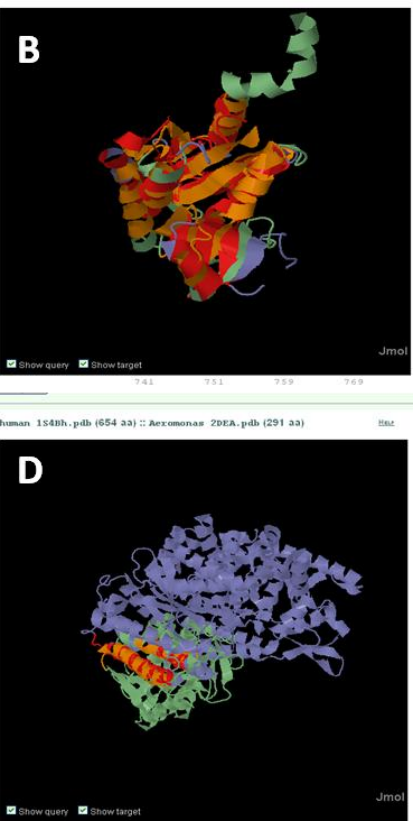

Figure 10: The super imposition protein structure from Aeromonas and Humans A: Flavohemoprotien, B: Guanylate kinase, C: DNA Topoisomerase, D: Oligopeptidase 
Bharath et al.,

\section{Molecular Docking Studies}

The inhibitors of all the four proteins were downloaded from pubchem data base, name, structure ID, structure and LogP of all the inhibitors subjected for docking are tabulated in Table 4, 5, 6 and 7 for Flavohemoprotein
Sci. Technol. Arts Res. J., April-June 2014, 3(2): 47-62

inhibitors, Guanylate kinase inhibitors, Topoisomerase inhibitors and Oligopeptidase inhibitors respectively (Rajesh et al., 2013). Flavohemoprotein inhibitors (4 and 8 ) and Oligopeptidase inhibitors (4 and 8 ) have not docked successfully.

Table 4: Flavohemoprotein Inhibitors

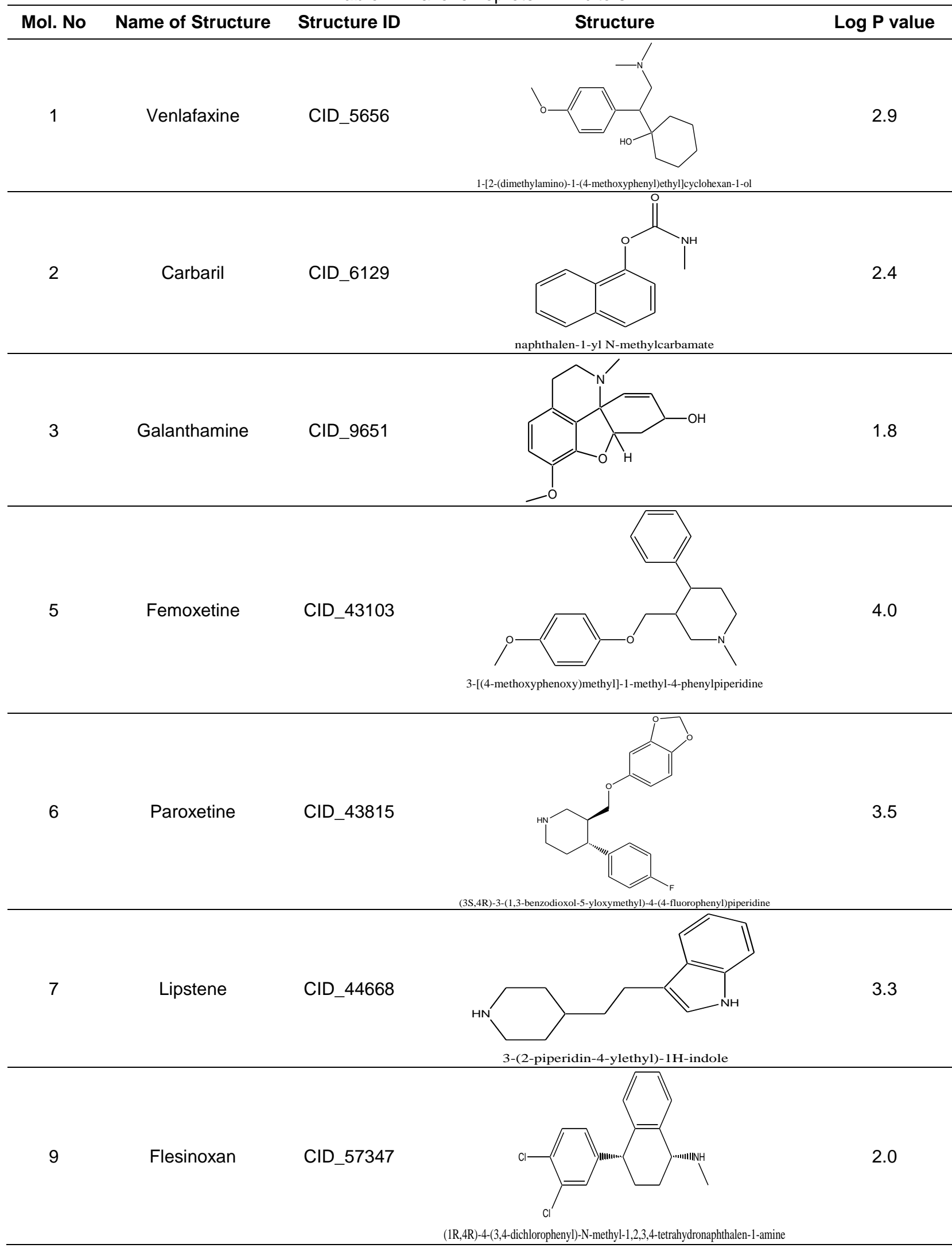


Table 5: Guanylate kinase inhibitor.

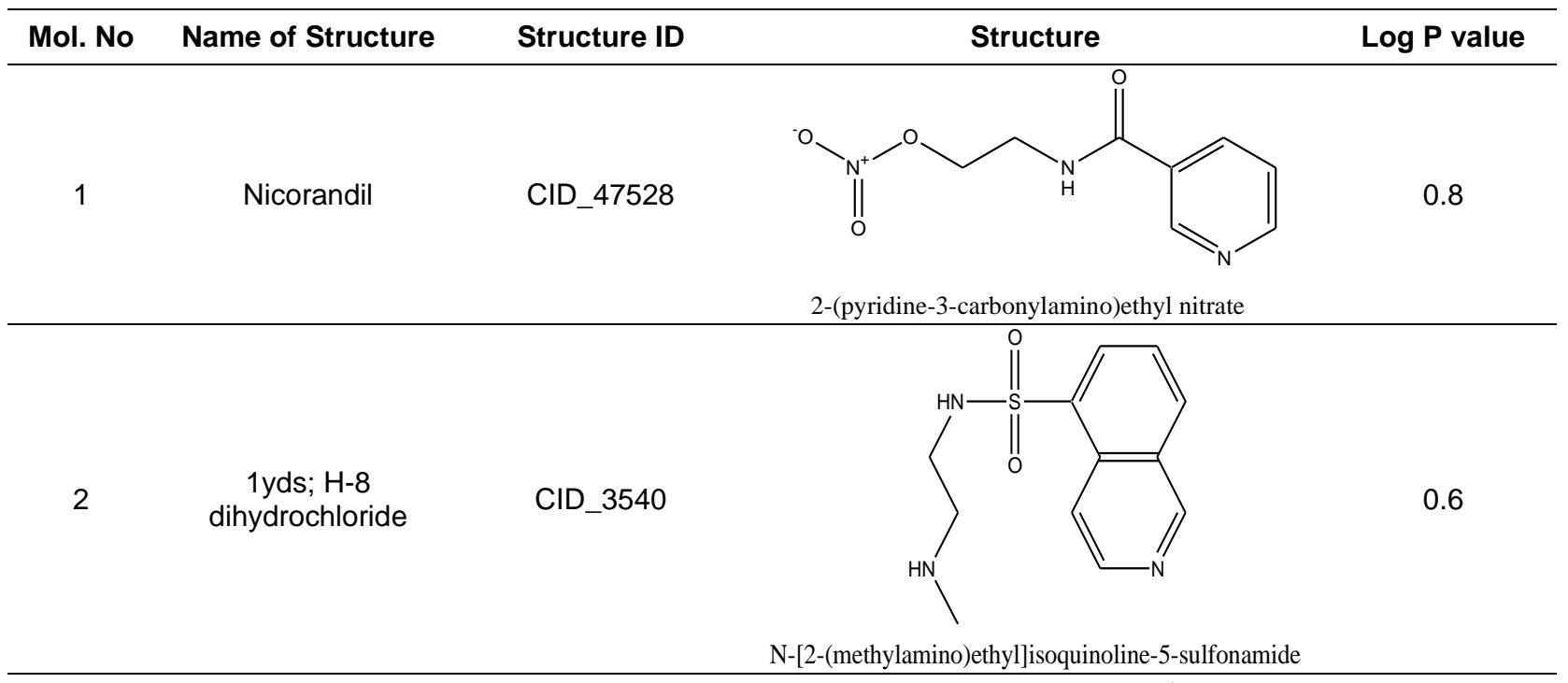
3
PP1 cpd; tyrosine
CID_10125426

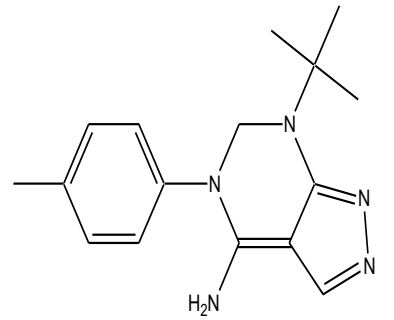

7-tert-butyl-5-(4-methylphenyl)-6H-pyrazolo[3,4-d]pyrimidin-4-amine

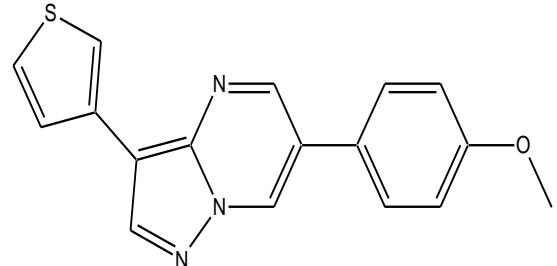

Nchembio.63Comp3

CID_5278396<smiles></smiles>

In the Molecular docking study of Flavohemoprotein inhibitors against Human and Aeromonas Flavohemoprotein, the inhibitor Hfhl9 showed minimum docking energy, binding energy, inhibition constant and 0.92 RMS value with Human Flavohemoprotein (Figure 11). The same molecule named Afhl9 showed minimum docking energy, binding energy, inhibition constant and 0.0 RMS value against Aeromonas Flavohemoprotein but less when compare with Hfhl9. The Afhl7 shown good results than other Aeromonas protein inhibitors (Figure 12). This kind of inhibitors cannot use as an antibacterial drugs. The minimum binding energy, docking energy, Inhibition constant and RMS value are tabulated in Table 8 and 9.
Molecular docking study of Guanylate kinase inhibitors against Human and Aeromonas Guanylate kinase showed that the inhibitor Hgkl5 showed minimum docking energy, binding energy, inhibition constant and 0.0 RMS value with Human Guanylate kinase protein (Figure 13). The same molecule named Agkl5 showed minimum docking energy, binding energy, inhibition constant and 0.0 RMS value against Aeromonas Guanylate kinase but less when compare with Hgkl5. The Agkl5 inhibitor showed good results than Hgkl5 (Figure.14). This kind of inhibitors can use as an antibacterial drugs. The minimum binding energy, docking energy, Inhibition constant and RMS value are tabulated in Table 10 and 11. 
Table 6: Topoisomerase inhibitors

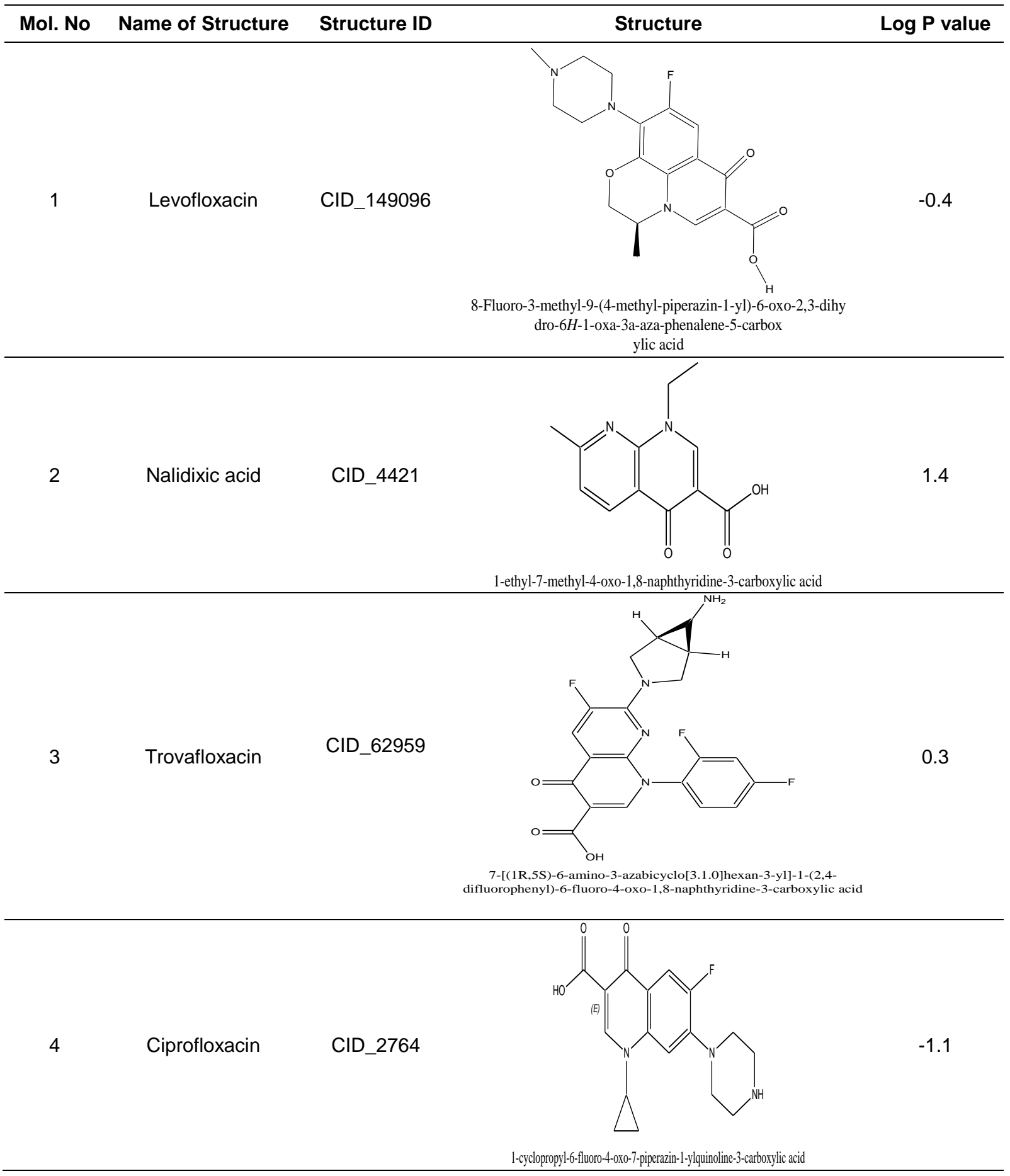

In the Molecular docking study of Topoisomerase inhibitors against Human and Aeromonas Topoisomerase, the inhibitor Htopl4 showed minimum docking energy, binding energy, inhibition constant and 0.0 RMS value with Human Topoisomerase (Figure 15). The same molecule named Atopl4 showed minimum docking energy, binding energy, inhibition constant and 0.0 RMS value against Aeromonas Topoisomerase but less when compare with Htopl4. The Atopl3 shown good results than other Aeromonas protein inhibitors (Figure 16). This kind of inhibitors cannot use as an antibacterial drugs. The minimum binding energy, docking energy, Inhibition constant and RMS value are tabulated in Table 12 and 13.
Eventually the molecular docking study of Oligopeptidase inhibitors against Human and Aeromonas Oligopeptidase was performed, here also the inhibitor Hopl1 showed minimum docking energy, binding energy, inhibition constant and 0.0 RMS value with Human Oligopeptidase (Figure 17). The same molecule named Aopl1 showed minimum docking energy, binding energy, inhibition constant and $0.0 \mathrm{RMS}$ value against Aeromonas Oligopeptidase but less when compare with Hopl1. The Aopl1 shown good results than other Aeromonas protein inhibitors (Figure 18). This kind of inhibitors cannot use as an antibacterial drugs. The minimum binding energy, docking energy, Inhibition constant and RMS value are tabulated in Table 14 and 15. 
Table 7: Oligopeptidase inhibitor.

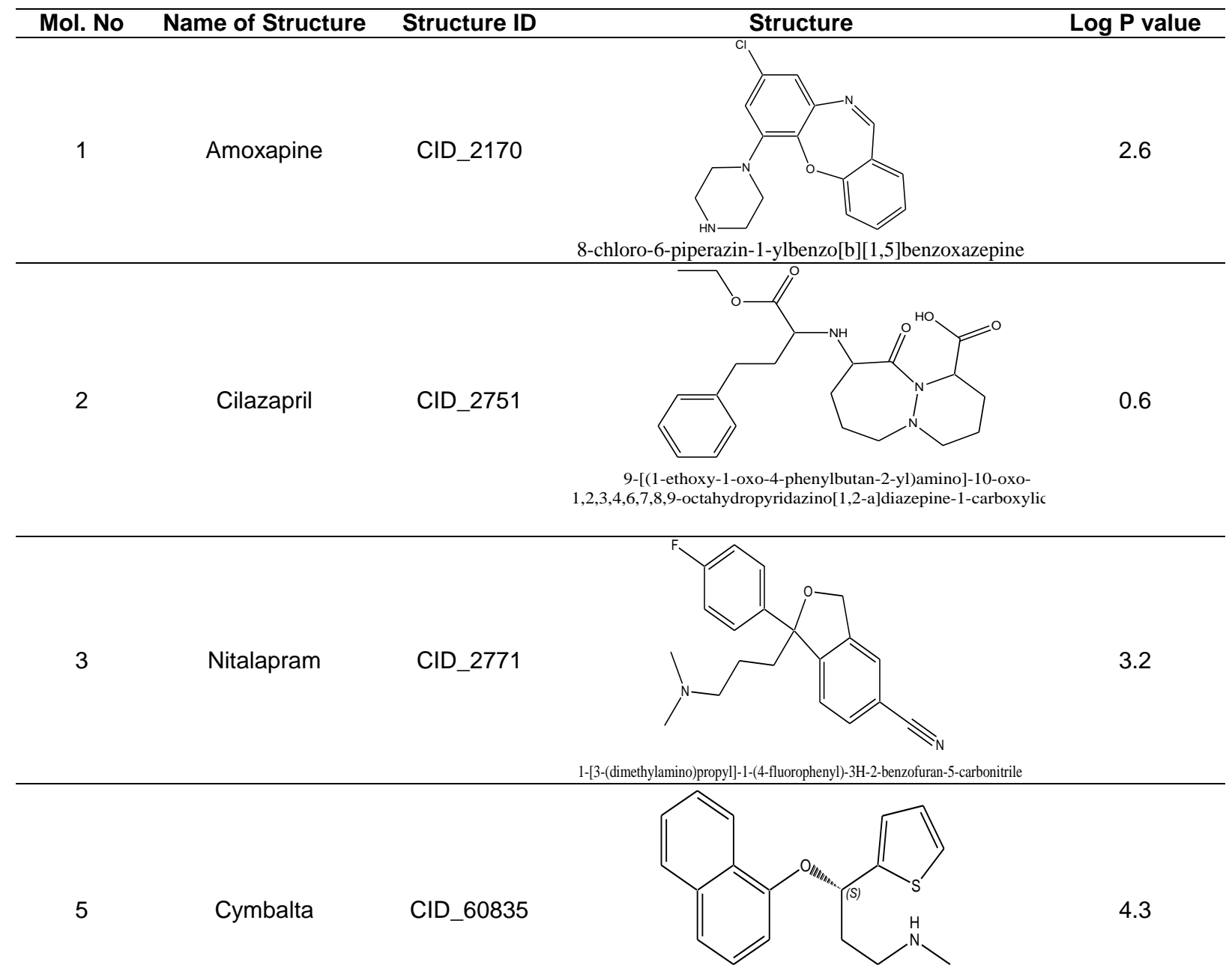

(3S)-N-methyl-3-naphthalen-1-yloxy-3-thiophen-2-ylpropan-1-amine

6 Duloxetine




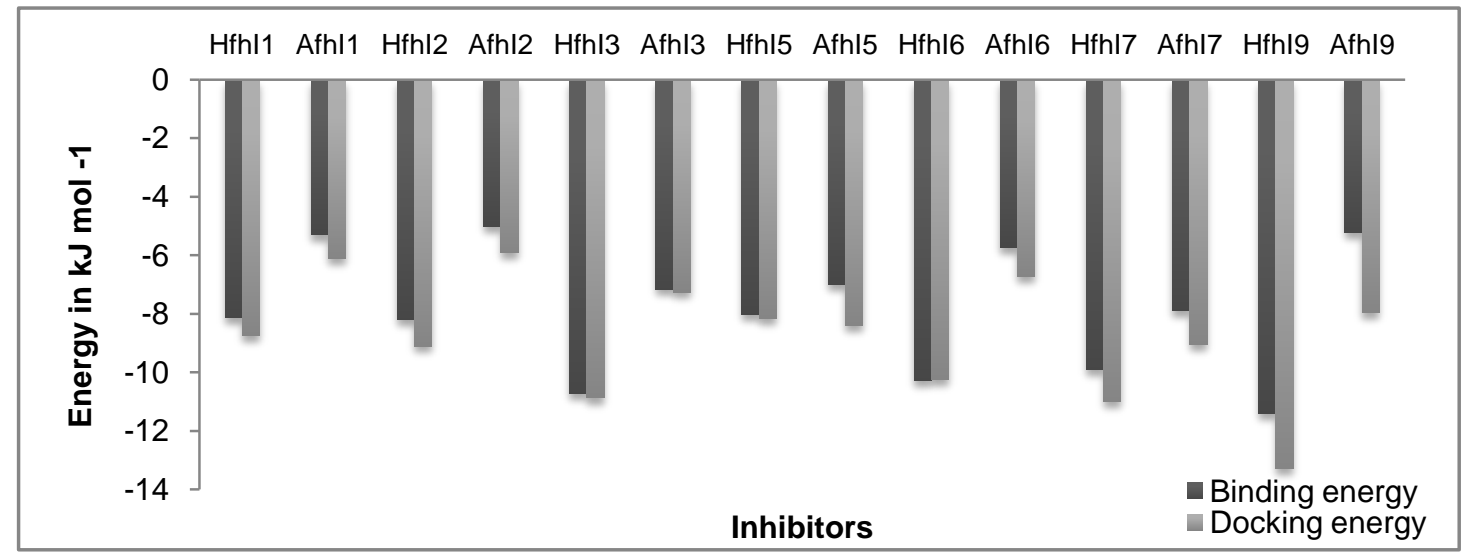

Figure 11: Graph showing binding energy and Docking energy of an inhibitors with both Human and Aeromonas Flavohemoprotein.

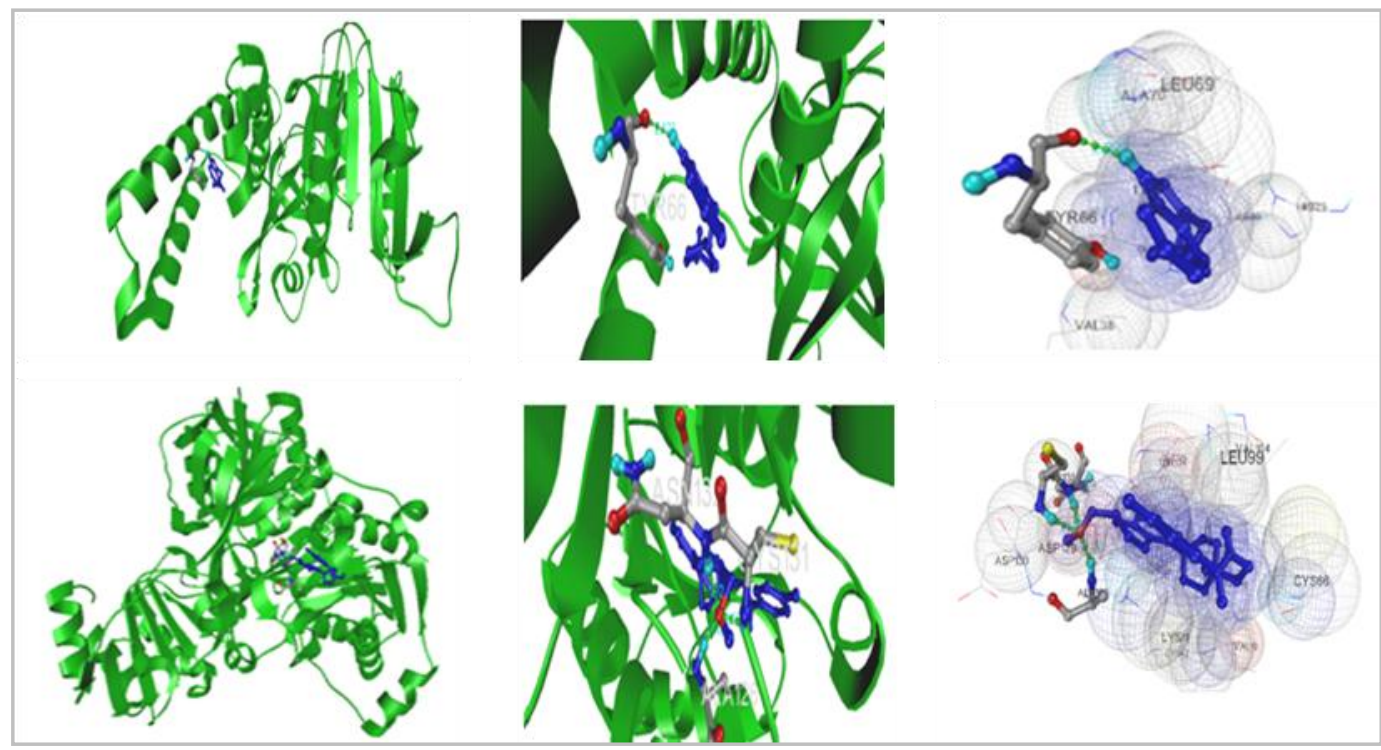

Figure 12: Docking of flavohemoprotein with the ligand flesinoxan, Top three corresponds to Aeromonas and Bottom three corresponds to human.

Table 8: Docking results for Aeromonas Flavohemoprotein (modeled protein)

\begin{tabular}{ccccc}
\hline Molecule number & Binding energy & Docking energy & Inhibition Constant & RMS \\
\hline Afhl1 & -5.31 & -6.13 & 0.000127 & 0.37 \\
Afhl2 & -5.01 & -5.92 & 0.000213 & 0.91 \\
Afhl3 & -7.16 & -7.26 & $5.62 \mathrm{e}-006$ & 0.1 \\
Afhl5 & -7.01 & -8.39 & $7.25 \mathrm{e}-006$ & 0.0 \\
Afhl6 & -5.75 & -6.72 & $6.12 \mathrm{e}-005$ & 1.51 \\
Afhl7 & -7.9 & -9.05 & $1.61 \mathrm{e}-006$ & 0.0 \\
Afhl9 & -5.23 & -7.97 & 0.000146 & 0.0 \\
\hline
\end{tabular}

Table 9: Docking results for Human Flavohemoprotein (1EFV)

\begin{tabular}{ccccc}
\hline Molecule number & Binding energy & Docking energy & Inhibition Constant & RMS \\
\hline Hfhl1 & -8.14 & -8.74 & $1.07 \mathrm{e}-006$ & 0.37 \\
Hfhl2 & -8.21 & -9.11 & $9.66 \mathrm{e}-007$ & 0.0 \\
Hfhl3 & -10.74 & -10.88 & $1.34 \mathrm{e}-008$ & 0.05 \\
Hfhl5 & -8.04 & -8.15 & $1.29 \mathrm{e}-006$ & 0.0 \\
Hfhl6 & -10.27 & -10.24 & $2.95 \mathrm{e}-008$ & 1.72 \\
Hfhl7 & -9.9 & -11.01 & $5.54 \mathrm{e}-008$ & 0.73 \\
Hfhl9 & -11.4 & -13.28 & $4.42 \mathrm{e}-009$ & 0.92 \\
& & & & \\
\hline
\end{tabular}




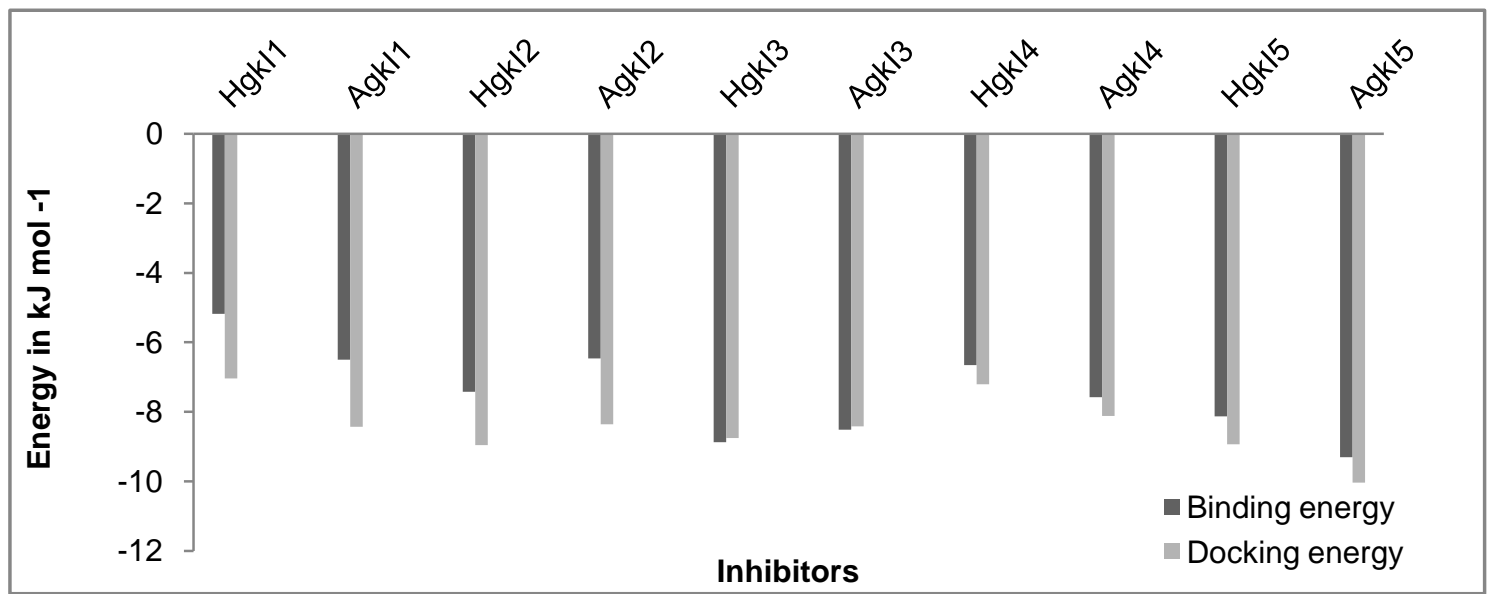

Figure 13: Graph showing binding energy and docking energy of an inhibitors with both Human and Aeromonas Guanylate kinase proteins.

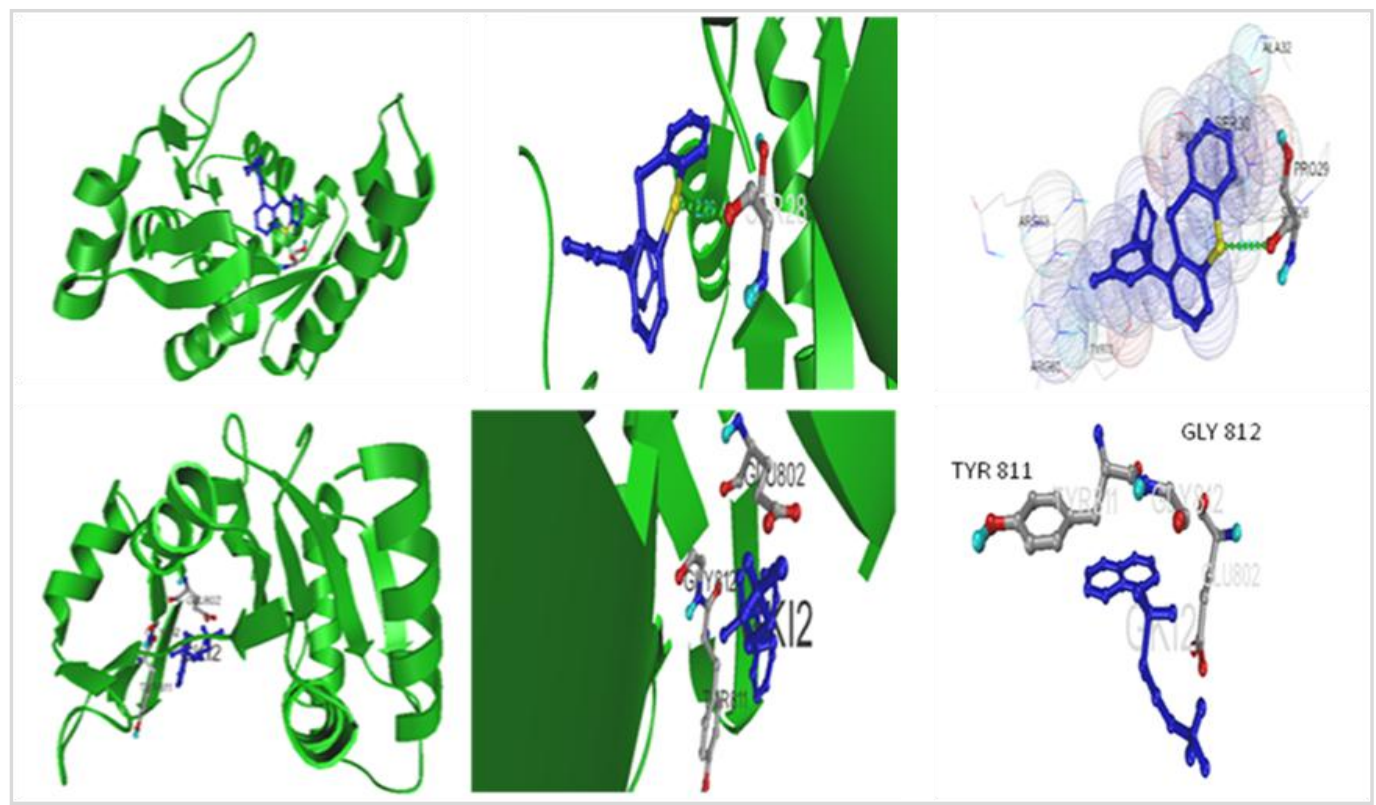

Figure 14: Docking of guanylate kinase with the ligand Nchembio.63-Comp3, Top three corresponds to Aeromonas and Bottom three corresponds to human Docking results.

Table 10: Docking results for Aeromonas Guanylate kinase (Modeled).

\begin{tabular}{ccccc}
\hline Molecule number & Binding energy & Docking energy & Inhibition Constant & RMS \\
\hline Agkl1 & -6.50 & -8.43 & $1.71 \mathrm{e}-005$ & 0.0 \\
Agkl2 & -6.46 & -8.35 & $1.84 \mathrm{e}-005$ & 0.0 \\
Agkl3 & -8.51 & -8.42 & $5.78 \mathrm{e}-007$ & 0.0 \\
Agkl4 & -7.58 & -8.12 & $2.76 \mathrm{e}-006$ & 0.0 \\
Agkl5 & -9.30 & -10.03 & $1.53 \mathrm{e}-007$ & 0.0 \\
\hline
\end{tabular}

Table 11: Docking results for Human Guanylate kinase (1KGD).

\begin{tabular}{ccccc}
\hline Molecule number & Binding energy & Docking energy & Inhibition Constant & RMS \\
\hline Hgkl1 & -5.18 & -7.04 & 0.000159 & 0.0 \\
Hgkl2 & -7.42 & -8.95 & $3.65 e-006$ & 0.0 \\
Hgkl3 & -8.87 & -8.75 & $3.17 e-007$ & 0.0 \\
Hgkl4 & -6.65 & -7.21 & $1.33 e-005$ & 0.0 \\
Hgkl5 & -8.13 & -8.93 & $1.10 \mathrm{e}-006$ & 0.0 \\
\hline
\end{tabular}




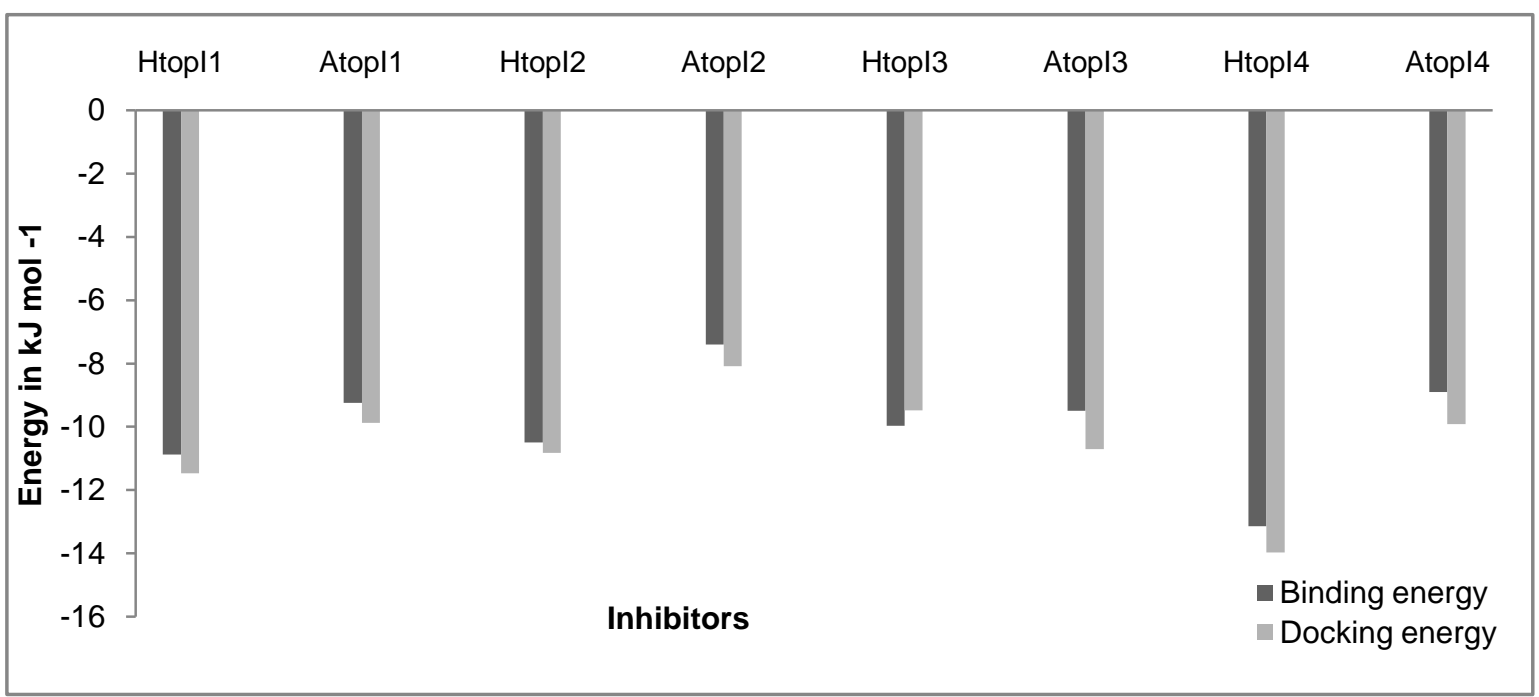

Figure 15: Graph showing Binding energy and Docking energy of an inhibitors with both Human and Aeromonas Topoisomerase proteins.

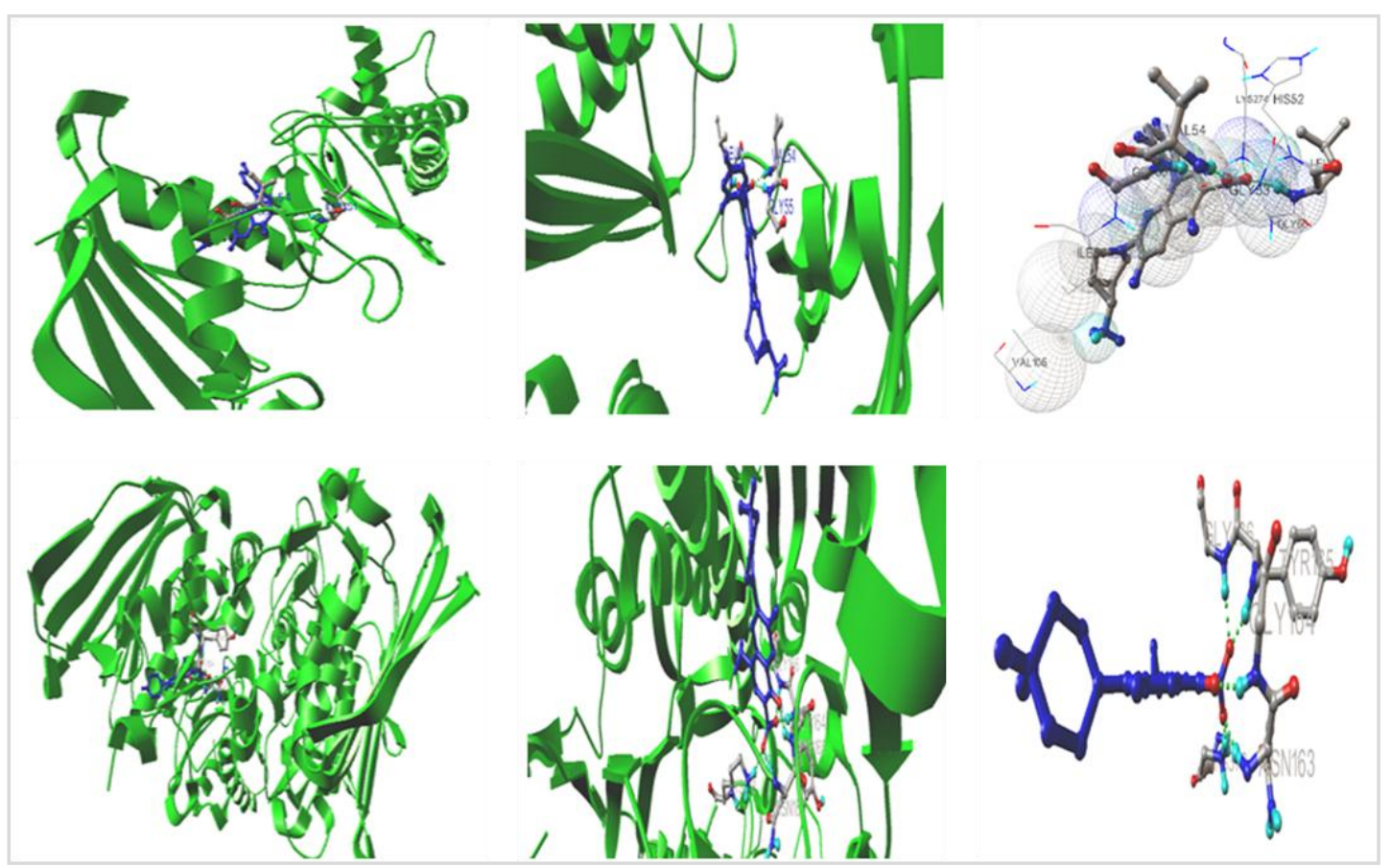

Figure 16: Docking of DNA Topoisomerase with the ligand Ciprofloxacin, Top three corresponds to Aeromonas and Bottom three corresponds to human.

Table 12: Docking results for Aeromonas Topoisomerase (Modeled)

\begin{tabular}{ccccc}
\hline Molecule number & Binding energy & Docking energy & Inhibition Constant & RMS \\
\hline Atopl1 & -9.24 & -9.87 & $1.69 \mathrm{e}-007$ & 0.0 \\
Atopl2 & -7.4 & -8.08 & $3.73 \mathrm{e}-006$ & 0.0 \\
Atopl3 & -9.49 & -10.70 & $1.11 \mathrm{e}-007$ & 0.84 \\
Atopl4 & -8.90 & -9.91 & $2.98 \mathrm{e}-007$ & 0.0 \\
\hline
\end{tabular}

Table 13: Docking results for Human Topoisomerase (1S16)

\begin{tabular}{ccccc}
\hline Molecule number & Binding energy & Docking energy & Inhibition Constant & RMS \\
\hline Htopl1 & -10.88 & -11.47 & $1.05 \mathrm{e}-008$ & 0.05 \\
Htopl2 & -10.49 & -10.83 & $2.05 \mathrm{e}-008$ & 0.0 \\
Htopl3 & -9.97 & -9.48 & $4.88 \mathrm{e}-008$ & 0.72 \\
Htopl4 & -13.14 & -13.97 & $2.35 \mathrm{e}-010$ & 0.0 \\
\hline
\end{tabular}




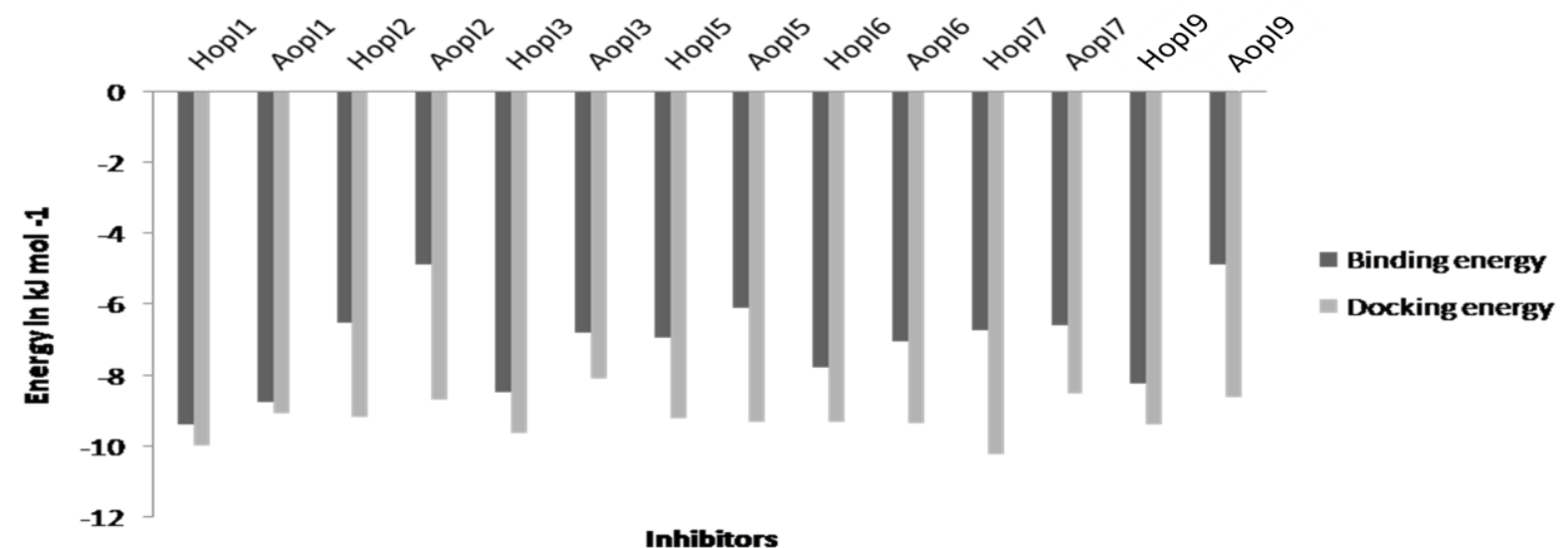

Figure 17: Graph showing Binding energy and docking energy of an inhibitors with both Human and Aeromonas Oligopeptidase proteins.

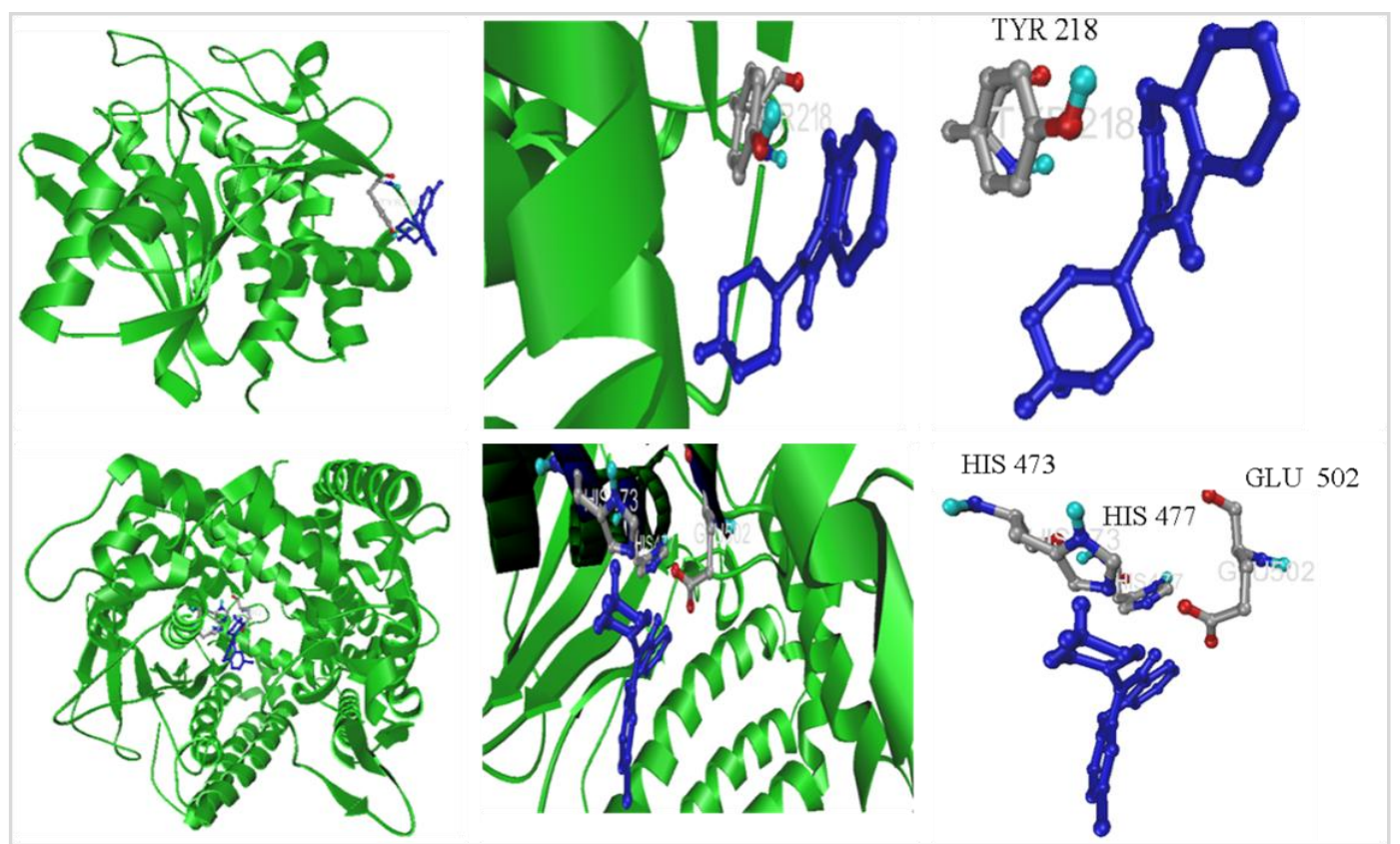

Figure 18: Docking of Oligopeptidase with the ligand Citalopram, Top three corresponds to Aeromonas and Bottom three corresponds to human.

Table 14: Docking results for Aeromonas Oligopeptidase (2DEA)

\begin{tabular}{ccccc}
\hline Molecule number & Binding energy & Docking energy & Inhibition Constant & RMS \\
\hline Aopl1 & -8.74 & -9.06 & $3.94 \mathrm{e}-007$ & 0.0 \\
Aopl2 & -4.88 & -8.67 & 0.000266 & 0.0 \\
Aopl3 & -6.77 & -8.08 & $1.1 \mathrm{e}-005$ & 0.0 \\
Aopl5 & -6.08 & -9.30 & $9.81 \mathrm{e}-006$ & 0.0 \\
Aopl6 & -7.04 & -9.34 & $6.97 \mathrm{e}-006$ & 0.0 \\
Aopl7 & -6.56 & -8.49 & $1.54 \mathrm{e}-005$ & 0.0 \\
Aopl9 & -4.87 & -8.59 & 0.000267 & 0.0 \\
\hline
\end{tabular}

Table 15: Docking results for Human Oligopeptidase (2DEA)

\begin{tabular}{ccccc}
\hline Molecule number & Binding energy & Docking energy & Inhibition Constant & RMS \\
\hline Hopl1 & -9.39 & -9.98 & $1.48 \mathrm{e}-007$ & 0.0 \\
Hopl2 & -6.50 & -9.17 & $1.73 \mathrm{e}-005$ & 0.0 \\
Hopl3 & -8.45 & -9.62 & $6.41 \mathrm{e}-007$ & 0.0 \\
Hopl5 & -6.91 & -9.19 & $8.55 \mathrm{e}-006$ & 0.0 \\
Hopl6 & -7.78 & -9.29 & $1.99 \mathrm{e}-006$ & 0.0 \\
Hopl7 & -6.71 & -10.23 & $1.21 \mathrm{e}-005$ & 0.0 \\
Hopl9 & -8.23 & -9.37 & $9.34 \mathrm{e}-007$ & 0.0 \\
\hline
\end{tabular}




\section{Bharath et al.,}

\section{CONCLUSIONS}

By the sequence analysis, structural analysis, and functional analysis of the four proteins taken from the human and bacteria, we have performed the docking studies by taking the inhibitors for four proteins. These inhibitors showed good docking energy with human proteins than Aeromonas hydrophila proteins which mediates neonatal septicemia, gastroenteritis and aquatic wound infections in mammals. Thus, we conclude that the taken inhibitors cannot be used as antibiotics, but the Agkl5 inhibitor showed good results than Hgkl5, this kind of inhibitors can be use as antibacterial drugs.

\section{REFERENCES}

Aebersold, R., Mann, M. (2003). Mass spectrometry-based proteomics. Nature 422:198-207.

Anderson, N.L., Anderson, N.G. (2002). The human plasma proteome -History, character, and diagnostic prospects. Molecular and Cellular Proteomics 1:845-67.

Andrzej, S., Martin, Z. (2003). Reduced Protein Model as a Tool in the Homology Modeling. Internet Electronic Conference of Molecular Design.

Bharath, B.R and Manjunatha, H. (2013). Flux Balance Analysis Based Model for the Identification of Potent Drug Target: A Novel Strategy. Science, Technology and Arts Research Journal 2(1):50-55.

Chopra, A.K., Xu, X.J., Ribardo, D., Gonzalez, M., Kuhl, K., Peterson, J.W., Houston, C.W. (2000). The Cytotoxic Enterotoxin of Aeromonas hydrophila Induces Proinflammatory Cytokine Production and Activates Arachidonic Acid Metabolism in Macrophages. Infection and Immunity 68: 2808-2818.
Sci. Technol. Arts Res. J., April-June 2014, 3(2): 47-62

Denis, M.D., Laura, Rossi. , Albert, M.B., Aravind, L, Eugene, V.K., and Eric, D.B. (2002). YjeQ, an Essential, Conserved, Uncharacterized Protein from Escherichia coli, Is an Unusual GTPase with Circularly Permuted GMotifs and Marked Burst Kinetics. Biochemistry 41: 11109-11117.

Galperin, Eugene, V.K. (1999). Searching for drug targets in microbial genomes. Current Opinion in Biotechnology 10: 571-578.

Joe, D., Zheng, O., Jeffery, T., Andrew, B., Yaron, T and Jie, L. (2006). CASTp: computed atlas of surface topography of proteins with structural and topographical mapping of functionally annotated residues. Nucleic Acids Research 34: 116-118.

Kudinha, T., swana, S.A.T., Simango, C. (2004). Antibiotic susceptibility patterns of Aeromonas species from humans, animals and water. The Southern African Journal of Epidemiology and Infection 19: 101-105.

Laurent, F., Marco, P., Philipp, B., Nicolas, H., Christian, J.A., Sigrist, K.H and Amos (2002) The PROSITE database, its status in 2002. Nucleic Acids Research 30: 235-238.

Michael, A.K., Daniel, J., Boris, H., Carolyn, A., Lawrence, James, J.C. (2007). A Common Mechanism of Cellular Death induced by Bacterial antibiotics. Cell 130: 797-810.

Rajesh, K.P., Manjunatha, H and Bharath, BR (2013) Simulated screening of flavonoids as probable antiHelicobacter pylori drug. Medicinal Chemistry Research 22: 4537-4546.

Stephen, F., Thomas, L.M., Alejandro, A.S., Jinghui, Z., Zheng, Z., Webb, M and David, J.L. (1997). Gapped BLAST and PSI-BLAST: a new generation of protein database search programs. Nucleic Acids Research 25: 3389-3402. 